\title{
Ten years of digital documentation of the archaeological site of the Monastery of Saint Hilarion in Tell Umm el-Amr, Gaza Strip
}

\author{
E. ALBY \\ Université de Strasbourg, INSA Strasbourg, CNRS, ICube Laboratory UMR 7357, Photogrammetry and Geomatics Group, 67000 \\ Strasbourg, France. \\ emmanuel.alby (at)insa-strasbourg.fr
}

KEY WORDS: Photogrammetry, Archaeology, Cultural Heritage, Recording

\begin{abstract}
:
The archaeological richness of a site is independent of its geopolitical context. The use of photogrammetry for the documentation of the monastery of Saint-Hilarion in the gaza strip illustrates the flexibility of the uses of this technique despite some obstacles linked to the situation. As access to the site on demand, depending on representation needs is not possible, means have been implemented to delegate the acquisition and allow continuity of surveys adapted to the evolution of archaeological excavations. Developments in acquisition techniques and methods can be incorporated into on-site practices and can also lead to improved processing of old data.
\end{abstract}

\section{INTRODUCTION}

Discovering the logic of facts in archeology is independent of the excavation context. This is part of what defines scientific practice. An archaeological site should be treated in the most neutral way by applying the principles of the discipline. The context takes part in the study, but it is desirable to limit this influence on the value of the results. This is the permanent effort that is being made within the framework of the archaeological study of the monastery of Saint-Hilarion in the Gaza Strip. Certain technical choices are made in relation to the context of the place, but the scientific results must be able to be evaluated independently of this context.

\section{CONTEXTS}

The archaeological site study takes place over a long period, if the exploitation of the place is motivated only by archaeological practice. This duration itself depends on the complexity of the excavation. The complexity of the excavation depends on the previous occupations of the site. To be able to understand and restore them, the investigation must be methodical. The remains are represented to allow their study by comparison. When it comes to furniture, the representation takes place after the excavation period. On the other hand, when they are discovered, the stratigraphic layer in which they are found must be able to be represented, because the discovery configuration will enrich the hypotheses regarding the occupation of the place. The concern is the same for the architectural elements, which cannot be moved without destruction, their documentation must be done as the excavation progresses. The representation of the excavation must be integrated into its progress. The documentation of archeology must incorporate this time. In technical applications to archeology, it is the object or characteristics of the site that creates scientific curiosity. The duration of the operation of the site is also an object of study. By anticipating technological advancement or integrating it over time, interventions can adapt to different contexts.

The geopolitical context of the Gaza Strip makes access difficult. The events of spring 2021 are a harsh reminder of the versatility of access and working conditions on site. These conditions contradict the sustainability necessary for this kind of intervention. Scientific reasons can be invoked to go there, but are not necessarily sufficient to go there depending on the representation needs of an excavation project. The survey phases are dictated by the progress of the excavations and the site enhancement work and must remain independent of the context of the excavation site.

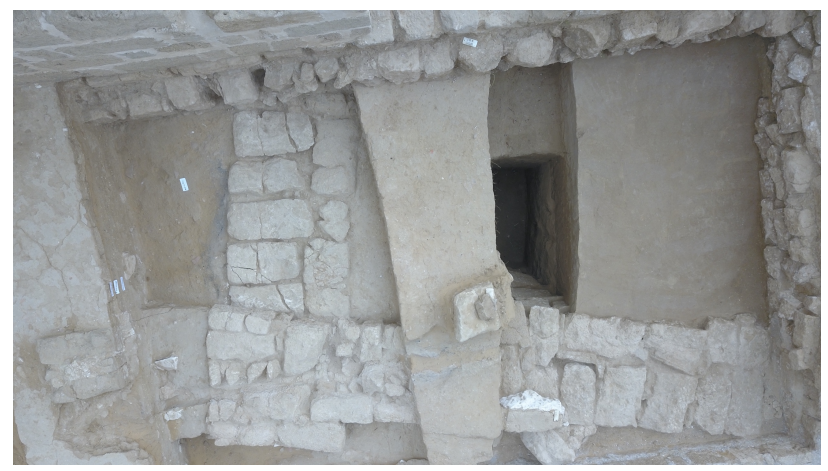

Figure 1. Several superimposed occupations visible by the different orientations of the wall frames

The archaeological site of the monastery of Saint-Hilarion is made up of several superimposed eras which require permanent monitoring for the recording of successive stratigraphic layers, the representation of which allows a consistency of the past life of the site. Figure 1 shows the multiple occupancies visible by differences in orientation of the walls. The orientations of the walls vary according to the structures and periods.

\section{DELEGATION OF PICTURES SHOOTING}

For obvious reasons, 3D scanning is done by photogrammetry to avoid being unable to import specific material such as a laser scanner, but also because it has been validated in its application to archeology ( Marín-Buzón, 2021). As access to the site is linked to that of the Gaza Strip, it is not possible to make acquisitions according to the needs imposed by the evolution of the site. One of the great advantages of the measurement technique of photogrammetry is the ability to separate acquisition from data processing. This is why choices were made so that the shots were taken regardless of the access possibilities. Only one mission dedicated to the photogrammetric survey could take place in 10 years of the project. Anything that could not be done at this time 
had to be done by delegation. Either the skills are already there, or they have to be created. To manage a large archaeological site, anywhere, you need a great management capacity and convinced and renewed support. In an area like the Gaza Strip, these conditions are not always met, we must continue anyway. The objectives of the photogrammetric mission are common to other sites: document, represent, conserve, enhance (Alby et al. 2013). Emergency documentation also takes part in this archaeological project due to the survival conditions of the site. It was acquired almost completely in 2012 to have documentation of the site regardless of its livelihood.

\section{UAV ON SITE}

The shooting direction has an influence on the quality of photogrammetric projects. Aerial photography allows projects to be optimized by getting closer to the direction of projection of the final performances (Colomina, 2014). The first mission in 2012 made it possible to take more than 15,000 terrestrial images while the site is close to a horizontal plane. To improve the shooting direction, the first kite tests were carried out and then the use of a drone was possible and widespread.

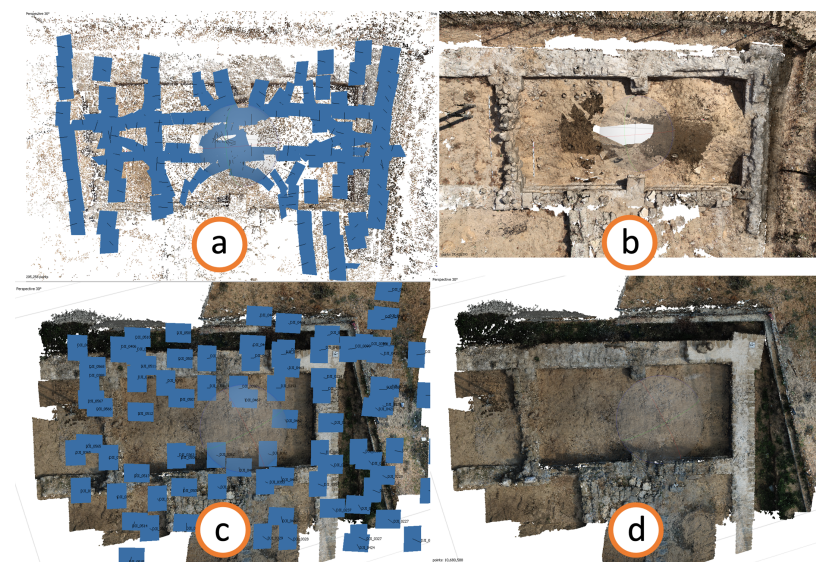

Figure 2. a): organization of shots from the ground and, b): point cloud in 2012, c): organization of drone shots and,

d): point cloud in 2021

Today with the use of a drone, the datasets evolve. Figure 2 shows the differences between the ground and drone views of the same room.

\section{ADVANCES IN CALCULATION ALGORITHMS AND SOFTWARE FEATURES}

The combination of computational and algorithmic performance makes it possible to process a much larger quantity of images than during the acquisition period. A major excavation was carried out in 2012, requiring 26 surveys of stratigraphic layers superimposed by photogrammetry. The acquisitions required 20 to 405 images per layer depending on their extent and the elements uncovered as shown in Figure 3. All these projects are piled up and have parts in common, in particular two walls between which the excavation has. occurred. In 2012, it was difficult to orient and process the bulk of the projects. To be able to have all the stratigraphic layers in the same coordinate system, you had to orient the images of each layer separately, scale them, produce each point cloud, and align them in a point cloud processing tool. In 2021, it is possible to calculate all the projects together automatically (3380 photos). Automation has increased as well as precision, since it all depends on a single phase of relative orientation (Moyano, 2020). The ergonomics of the tools also play a role since it is much easier to assign subgroups of images from the same project to create separate clouds. In this case, for a single project with all the images for the 26 different layers, only one orientation was made and 26 different clouds were produced.
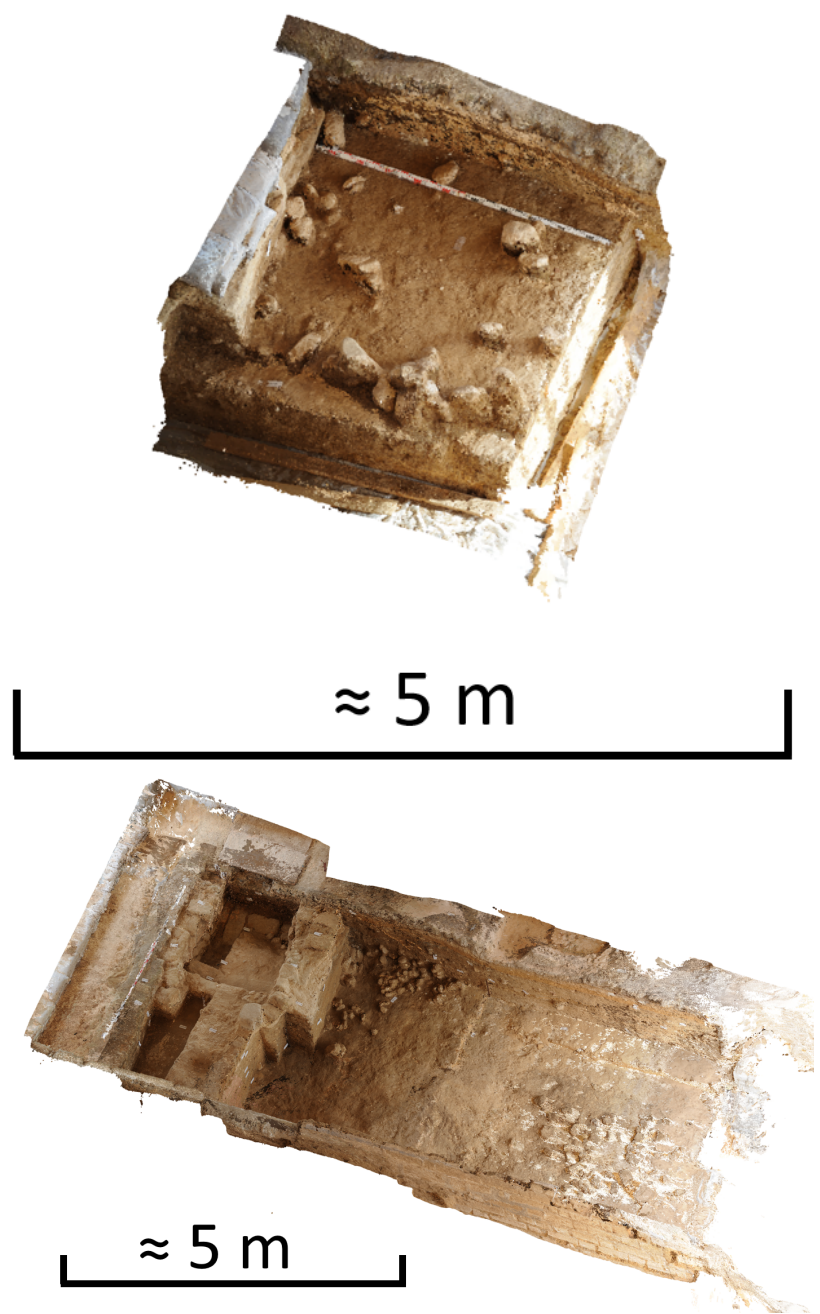

Figure 3 : two point clouds requiring 20 images at the top and 405 at the bottom

We must also take into account the evolution of the techniques and tools available (Remondino, 2014). Over time, the means and methods change, in 2011, the automation provided by the sfm made it possible to acquire and process a large quantity of photos using the multi-image project technique.

The possibilities offered by the sfm at the time suggested unsuspected orientation capacities and, in anticipation of the capacities of the tools, made it possible to calculate everything today in a single process.

The production of sections illustrating the layering is greatly facilitated as shown in Figures 4 and 5.

To dig you need workers, you have to pay them, and have permanent jobs to entrust to them. The course of an excavation is an alternation of stripping, cleaning and representation. This last step does not require a worker and therefore its duration must be reduced as much as possible to resume the first two as quickly as possible. The representation of excavations by photogrammetry saves time and searches almost continuously (Alby, 2015). 

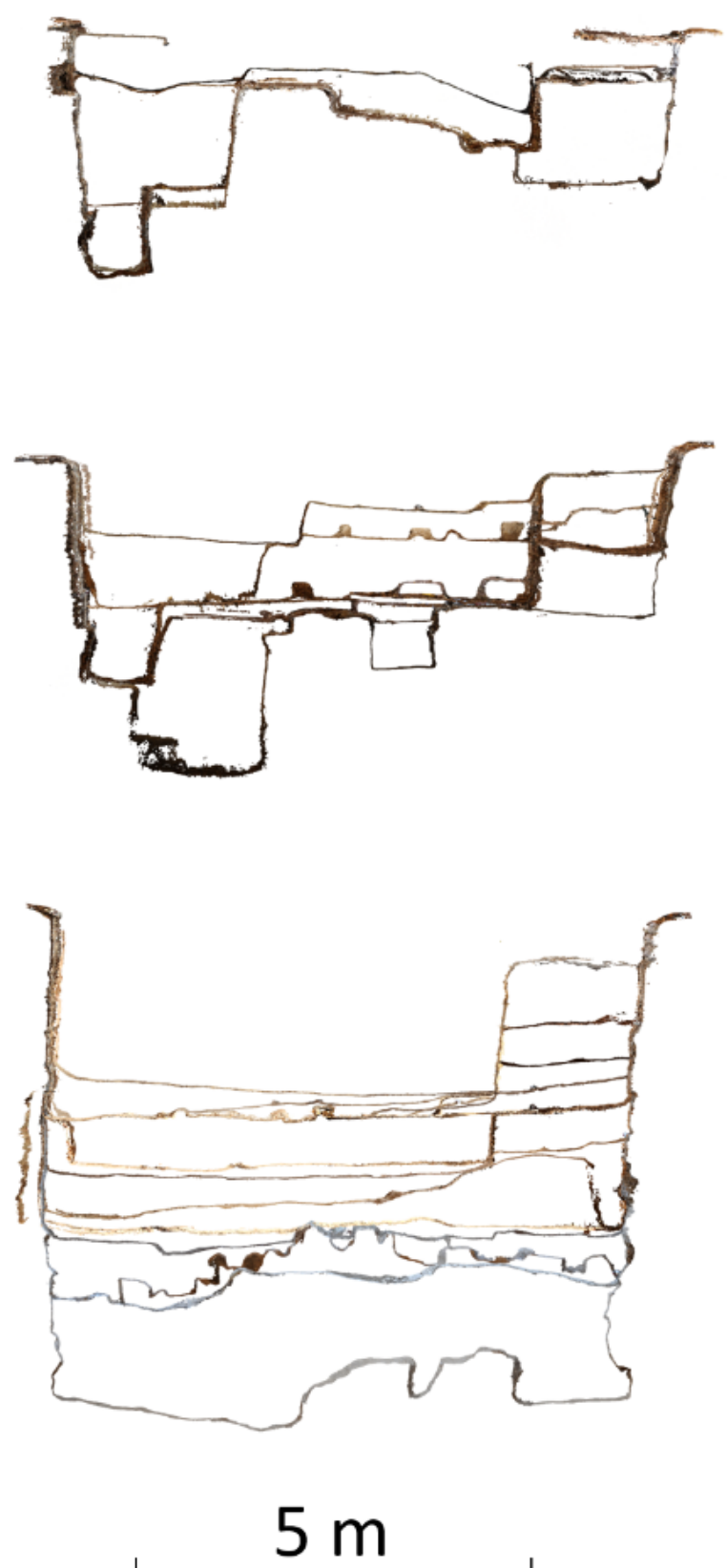

Figure 4. Three cross sections in the overlaid clouds of the excavation

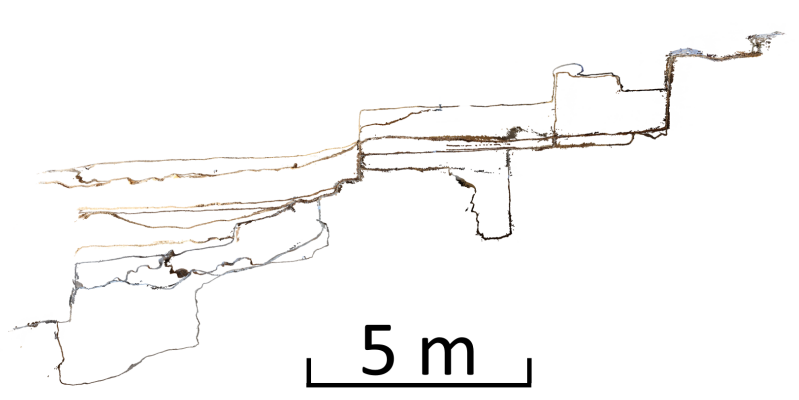

Maintaining the site changes its appearance. Indeed the site is made up of walls on a few rows of blocks and must be maintained in condition by consolidation and repair of masonry. Figure 6 compares the same wall angle separated by 10 years of maintenance and upgrading. This permanent development limits automatic recognition between excavation periods. The vagaries of the situation did not allow the canvas to be produced at the same time as the main photogrammetric survey, which means that the maintenance of the site reduced the common areas that could be detected automatically.

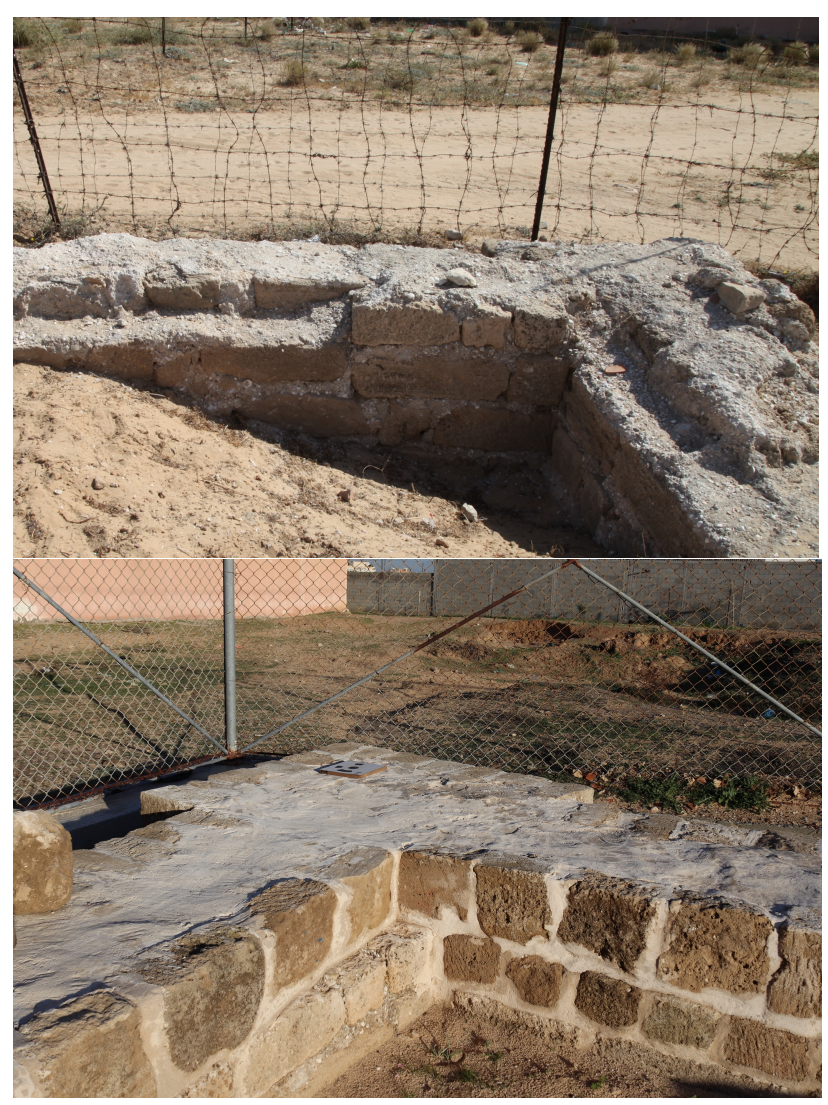

Figure 6. The same angle of a ruined building in 2012 and 2021.

Unlike other interventions (Alby et al. 2019), topographic preparation could not be done at the time of photogrammetric acquisition. Permanent targets have recently been put in place to facilitate repeat processing and acquisitions. Using targets allows you to pick up the same areas and easily overlay data regardless of how the data changes. So, whether excavated or reconstructed, shape no longer has an influence on the ability to merge data.

Beyond the programming of the excavations, the enhancement and protection of the site requires work that generates occasional archaeological interventions for a foundation block or the installation of footbridges. Figure 7 shows the juxtaposition of the excavation and site development issues.

Figure 5. Longitudinal section 


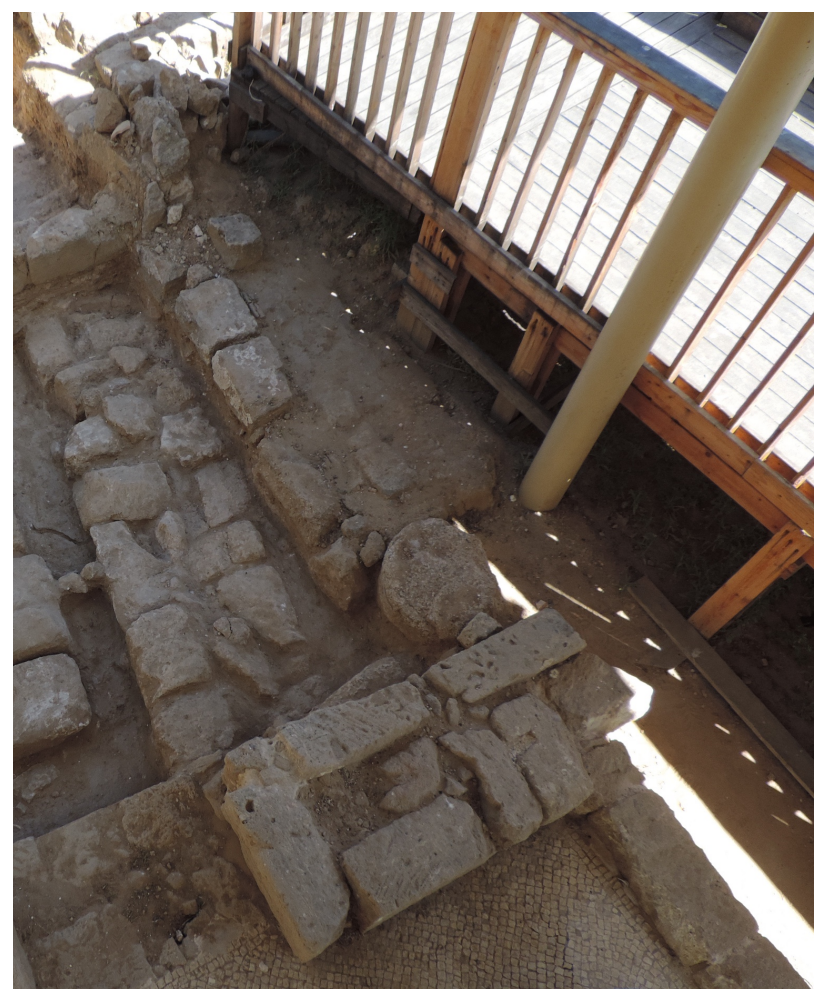

Figure 7. Juxtaposition of structure and access for visitors with the excavations

The 3D models produced must be able to be combined with existing representations and future excavations. An archaeological site must be protected and maintained in good condition. Temporary protections must be removed for photogrammetric acquisition. They appear at the limits of the data sets and must not interfere with processing. The groups of images for the orientation of the datasets are different from those chosen to produce the 3D data.

Drone acquisition is now possible on the site and allows the production of data sets consistent with the scope of the site. Miniaturization and affordable prices have made it possible to have this kind of device in the Gaza Strip. The production of orthophoto is facilitated by this change of perspective and the acceleration of the acquisition.

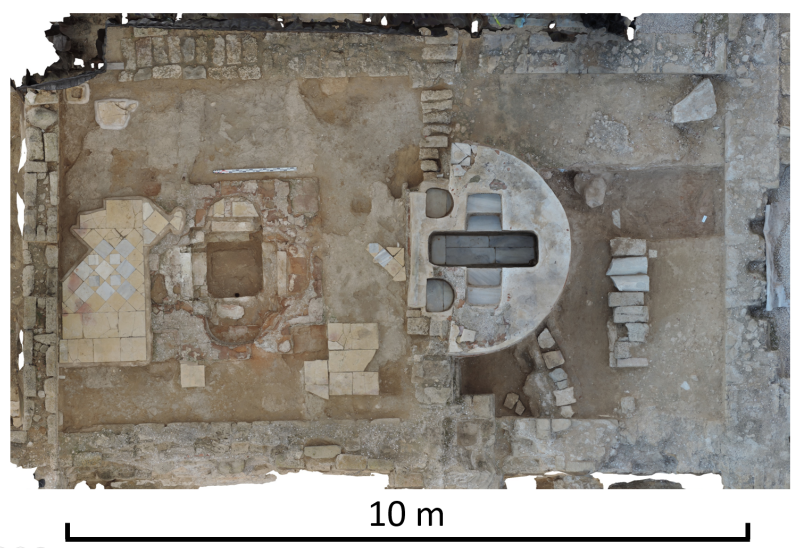

Figure 8. ortho-photo of the baptistery made from images taken by the site manager.
The representations produced are mainly orthophoto of the ground, like the one in figure 8. Some orthophoto of vertical sections were also necessary. Drone shooting greatly facilitates the acquisition of images in the direction of the projections of the final orthophoto, which facilitates the production process and improves the quality of models and products.

The direct use of 3D models is starting to be seen as a potential use, especially for site reconstruction and production of virtual tours.

\section{METHODS AND DATA QUALITY}

The delegation of the shooting has an influence on the quality of the data produced both geometrically and from a radiometric point of view. The quality of the dataset has a great influence on the quality of the final data but also on the processing chain.

The survey must be carried out according to the needs related to the progress of the sites (excavation and recovery). It is not the random obtaining of authorization to enter a territory that must impose the temporality of the acquisition. It is for this reason that it is necessary that there is at least one competent operator present at all times. From the year 2020 and the health situation, this need has become even more pressing. The need to delegate the photogrammetric survey was imposed by the double confinement of the population. As the project is long-term, it is relevant to consider the training of operators. Photography is one of the archaeologist's tools. The camera is already omnipresent on the excavation site and now in every pocket with smartphones. Assuming that it is available to everyone is interesting for training remote operators, but the downside is that photogrammetry seems easily accessible without prerequisites and the production of data sets can seem accessible to everyone. Datasets that can be extracted from 3D models are not necessarily good datasets. Advances in knowledge and developments in photogrammetry make it possible to create 3D data from non-optimal datasets, but it is always preferable to aim for the best possible dataset, if only to obtain the best quality or to limit the post-treatments. We must raise awareness of the methodical realization of acquisitions to optimize the survey and its treatments. Understanding how the technique works allows you to effectively manage a complex survey. Finally, mastering the theory gives access to the quality of the measurement and to possibilities for improvement.

For the creation of good data sets, it should also be taken into account that outside the excavation areas, the survey must be done with clean areas, cleaned of sand and vegetation.

\section{CONCLUSION}

The management of the documentation data of an archaeological site requires an integration of the techniques used taking into account the evolution of techniques allowing deferred processing on the one hand, but also the anticipation of the evolution of techniques for an optimization of their use over technological advancements, on the other hand. The specific context of the monastery of Saint-Hilarion requires the delegation of the photogrammetric survey. The training of those responsible for the surveys must also incorporate changes in methods so that they are taken into account and that the site documentation benefits.

\section{ACKNOWLEDGEMENTS}

René ELTER Director of French-Palestinian archaeological mission in Tell Umm el-Amr, Gaza strip Lorraine university, EA 1132 Hiscant-Ma. 
French Biblical and Archaeological School (EBAF), 6 Nablus Road P.O.B. 1905391190 Jerusalem JERUSALEM.

First International Emergency - Occupied Palestinian Territory.

\section{REFERENCES}

Alby, E., Elter, R., Ripoche, C., Quere, N., and INSA de Strasbourg: Close range photogrammetry applied to the documentation of an archaeological site in Gaza strip, Palestine, Int. Arch. Photogramm. Remote Sens. Spatial Inf. Sci., XL5/W2, 19-24, https://doi.org/10.5194/isprsarchives-XL-5-W219-2013, 2013.

Alby, E.: Point cloud vs drawing on archaeological site, Int. Arch. Photogramm. Remote Sens. Spatial Inf. Sci., XL-5/W7, 7-11, https://doi.org/10.5194/isprsarchives-XL-5-W7-7-2015, 2015.

Alby, E., Vigouroux, E., and Elter, R.: Implementation of survey and three-dimensional monitoring of archaeological excavations of the Khirbat al-Dusaq site, Jordan, Int. Arch. Photogramm. Remote Sens. Spatial Inf. Sci., XLII-2/W15, 41-47,
https://doi.org/10.5194/isprs-archives-XLII-2-W15-41-2019, 2019.

Colomina, I. Molina, P. Unmanned aerial systems forphotogrammetry and remote sensing: A review, ISPRS J.Photogramm. Remote Sens. $92 \quad$ (2014) 7997,https://doi.org/10.1016/j.isprsjprs.2014.02.013

Marín-Buzón, C.; Pérez-Romero, A.; López-Castro, J.L.; Ben Jerbania, I.; Manzano-Agugliaro, F. Photogrammetry as a New Scientific Tool in Archaeology: Worldwide Research Trends. Sustainability 2021, 13, https://doi.org/10.3390/su13095319

Moyano, J.; Nieto-Julián, J.E.; Bienvenido-Huertas, D.; MarínGarcía, D. Validation of Close-Range Photogrammetry for Architectural and Archaeological Heritage: Analysis of Point Density and 3D Mesh Geometry. Remote Sens. 2020, 12, 3571. https://doi.org/10.3390/rs12213571

Remondino, F., Spera, M.G., Nocerino, E., Menna, F. and Nex, F. State of the art in high density image matching. Photogram Rec, 2014 29: 144-166. https://doi.org/10.1111/phor.12063 